\title{
CARTOGRAFIAS LITERÁRIAS: A ANTOLOGIA E O ENSINO
}

\section{LITERARY CARTOGRAPHIES: THE ANTHOLOGY AND TEACHING}

\author{
Analice de Oliveira Martins* \\ IFF
}

Resumo: Este artigo pretende avaliar alguns impactos dos Estudos Culturais sobre os Estudos Literários e suas repercussões e desdobramentos no Ensino de Literatura, em particular, da literatura brasileira. A politização do discurso literário é consequência do fértil diálogo entre a Antropologia, a Sociologia e a Literatura. Nesse sentido, será discutido, do ponto de vista teórico, o boom de antologias centradas em uma das variantes do processo mais complexo da identidade cultural pós-moderna e suas implicações para o Ensino, buscando avaliar vantagens e desvantagens ocasionadas por tal tendência do mercado editorial brasileiro. Entre as antologias a serem analisadas, destacam-se 25 mulheres que estão fazendo a nova literatura brasileira (2004), + 30 mulheres que estão fazendo a nova literatura brasileira (2005), Entre nós: contos sobre homossexualidade (2007), Questão de pele: contos sobre preconceito racial (2009), de Luiz Ruffato, e Primos: história da herança árabe e judaica (2010).

Palavras-chave: Antologia. Ensino. Estudos Culturais.

Abstract: This article intends to evaluate some impacts of Cultural Studies on Literary Studies and its repercussions and developments in Literature Teaching, in particular, from brazilian literature. The politicization of literary discourse is a consequence of the fertile dialogue between Anthropology, Sociology and Literature. In this sense, the theoretical boom of anthologies focusing on one of the variants of the more complex process of postmodern cultural identity and its implications for teaching will be discussed, seeking to evaluate the advantages and disadvantages caused by such a tendency in the publishing market brazilian. Among the anthologies to be analyzed, 25 mulheres que estão fazendo a nova literatura brasileira (2004), + 30 mulheres que estão fazendo a nova literatura brasileira (2005), Entre nós: contos sobre homossexualidade (2007), Questões de pele: contos sobre preconceito racial (2009), de Luiz Ruffato, e Primos: histórias da herança árabe e judaica (2010).

Keywords: Anthology. Teaching. Cultural Studies.

\section{Introdução}

Em grego, a palavra anthós significa flor. Uma antologia é, portanto, um tratado acerca das flores, um florilégio. O desconhecimento das origens das palavras costuma afastar os significados mais profundos dos conceitos.
* Professora Titular do Instituto Federal Fluminense com PósDoutorado em Literatura Brasileira pela Università degli Studi Roma Tre. E-mail: analice.martins@ terra.com.br. 
Para o senso comum, as antologias cumprem a função de recolher e selecionar o que deve ser guardado como representativo da obra de um artista, de uma época, de um estilo, porque são suas flores mais expressivas. Resta saber quem diz o que é mais expressivo? Os críticos especializados, os leitores, as universidades, as academias? Quem delibera sobre o valor histórico que não necessariamente é o estético? Mais delicado ainda é perceber que valor e gosto nem sempre andam de mãos dadas. As editoras que as publicam contratam um organizador a quem cabe a responsabilidade pela escolha dos textos e a quem deveria também caber a explicitação dos critérios para o recorte apresentado. Se assim fosse sempre, as discordâncias entre as preferências de leitores - especializados ou não - se reduziria. Mas, na realidade, são os ruídos na compreensão que estabelecem o confronto de opiniões.

Do ponto de vista pedagógico e didático, as antologias podem ser um convite à leitura mais aprofundada das obras dos escritores nelas envolvidos ou uma espécie de mapeamento da literatura que se desconhece. Saber escolhê-las e usá-las em uma sala de aula é projeto de outra monta e razão deste artigo. O fato é que, no Brasil do século XXI, chama-se antologia ao que o tempo de maturação e de reflexão ainda não colocou à prova. Chamase antologia ao que não passou por esse crivo e que, embora selecionado e organizado por alguém de credibilidade, já se vende como o que há de mais significativo. Ou seja, reuniões de textos que deveriam ser apresentadas como coleções ou coletâneas são oferecidas pelo mercado editorial com o selo e a recomendação de “antológicos”.

O que ocorre, no mercado editorial brasileiro no início do século XXI, sem querer problematizar desnecessariamente a questão, pode ser equivalente a vender gato por lebre. Como chamar de antologia a reunião de textos que foram feitos por encomenda para constarem de um livro como Os cem menores contos do século, organizado pelo escritor Marcelino Freire, que tem muitos méritos, mas antologia não é. O mesmo se aplica às publicações Pátria Estrangeira e Os apóstolos, da editora Nova Alexandria, compostas de contos feitos com exclusividade para seus projetos temáticos. Nada contra, a priori, em relação a essas seleções em que estão as novas faces da literatura brasileira contemporânea que devem ser conhecidas para que se tenha a medida e a compreensão do tempo presente.

Foi classificada como antologia a publicação da prestigiada revista literária inglesa Granta sobre aqueles que eram, segundo a opinião de sete jurados especializados, os vinte melhores jovens escritores brasileiros - aqueles com menos de 39 anos. A revista recebeu 247 inscrições de interessados que tivessem ao menos um texto já publicado ou contrato assinado para publicar obra de ficção. O resultado desta seleção foi anunciado durante a 10 ${ }^{\mathrm{a}}$ edição da FLIP (Festa Literária Internacional de Paraty), em 2012. O anúncio provocou, à época, a polêmica sobre os "vinte escritores mais odiados do Twitter”. A grita é sempre mais alta quando a expressividade, 
que deve nortear qualquer seleção que se deseja representativa, está atrelada a qualificações como "melhores, maiores" etc.

A formação do leitor, no âmbito da Educação Básica no Brasil, está vinculada às exigências legais do MEC (Ministério da Educação e Cultura), da LBD (Lei de Diretrizes e Bases), e orientada pelos PCN (Parâmetros Curriculares Nacionais) e pelas políticas públicas da Educação. Ainda assim, via de regra, fracassa em qualquer das dimensões e funções da leitura literária, tais como a lúdica, a cognitiva, a pragmática, a sinfrônica e a evasiva. Fracassa também qualquer que seja seu objeto discursivo: obras canônicas, contemporâneas, de temáticas, gêneros e tipologias diferentes. Esse artigo não pretende diagnosticar nem contextualizar as causas dessa triste realidade, muito embora algumas dessas razões sejam tangenciadas na tentativa de compreender o papel que cumprem as antologias literárias na formação escolar do aluno-leitor, especialmente, a partir da última década do século XX, que assistiu a uma espécie de boom de publicações as mais variadas abarcadas pelo rótulo de antologias. Uma espécie de guarda-chuva multicolorido que não escamoteia os tentáculos do mercado editorial.

Mais do que fazer um levantamento de títulos e números, de caráter empírico-quantitativo, essa pesquisa pretende pensar as vantagens e desvantagens da adoção de antologias literárias na formação escolar brasileira do final do século XX e do início do século XXI em consonância com a emergência de políticas afirmativas ligadas aos Estudos Culturais e suas possíveis intervenções sociais, ou seja, quando a leitura literária é entendida como um processo de formação cidadã, além de suas dimensões cognitiva e estética.

As questões a serem discutidas, portanto, serão direcionadas à eclosão do que se poderia chamar de "literatura de escaninhos”, um título também pensado por mim para esta reflexão, uma vez que alude a agrupamentos e segmentações preocupados com a visibilidade de construções identitárias, para além dos critérios outrora reguladores das antologias, tais como: gênero literário, periodização, temática, geografia cultural.

Critérios como gênero, etnia, faixa etária, geração somam-se aos critérios paradigmáticos. Mais do que isso, a concepção mesma de antologia é esgarçada, revista, e o presente, por paradoxal que seja, se antologiza.

Em um país em que a formação do professor se precariza a cada década, ${ }^{1}$ escolhas, indicações e recusas de obras dessa natureza ficam às vezes à mercê apenas da oferta do mercado editorial e de suas estratégias glamourizadas de divulgação.

\section{Definições e funções}

Descartada a intenção de fazer um percurso historiográfico das antologias publicadas no Brasil a partir do século XIX, faz-se necessário estabelecer uma definição que possa dar conta de um fenômeno relativamente recente
${ }^{1}$ Um interessante diagnóstico sobre a formação de professores pode ser encontrado no artigo de Bernadete A. Gatti, intitulado "Formação inicial de professores para a educação básica: pesquisas e políticas educacionais”, publicado em 2014 (http://www. fcc.org.br/pesquisa/ publicacoes/eae/ arquivos/1899/1899. pdf). Nele, a autora discute aspectos que contribuem para o que estou chamando de precarização da formação do professor: improvisação de professores; ausência de uma política nacional específica para as licenciaturas; pouca atenção às pesquisas sobre o tema; diretrizes curriculares isoladas por curso; currículos fragmentados; estágios sem projeto e acompanhamento; aumento da oferta de cursos a distância; despreparo de docentes das instituições de ensino superior para formar professores; e características socioeducacionais e culturais dos estudantes, permanência e evasão nos cursos. Aliados a tais aspectos encontram-se os baixos e aviltantes salários do professor brasileiro de escolas públicas de ensino fundamental e médio, conforme relatório de Education at a glance, na edição de 2017. 
no Brasil - o boom das antologias - e seu atrelamento às condições mais plurais e globalizadas de nossa realidade.

Como já afirmado preliminarmente, por definição etimológica, “antologia” (do grego anthología) é uma seleção de flores, um florilégio. Estendida a conceituação às práticas literárias, constitui uma antologia a seleção criteriosa de obras e autores pertencentes a uma época, a uma geração, a uma nacionalidade, a um gênero literário, a uma temática. Ora, é justamente aí, na condição de escolha, que entram as vantagens e as desvantagens de sua propedêutica na formação escolar do aluno-leitor. É desse público leitor que estou tratando.

Quem seleciona? Quem está autorizado a selecionar? Seleciona com que critérios e com que intenções? Caso essas questões não sejam levadas em consideração, na indicação de antologias para leitura na escola, corre-se o risco de uma problemática descontextualização político-literária de obras e autores. Corre-se também o risco de um vale-tudo literário com apelo falsamente democratizador.

O escritor Luiz Ruffato, para além de sua produção ficcional, tem ocupado importante espaço na cena literária com a organização, nas últimas duas décadas no Brasil, de várias antologias, entre as quais destaco, por razões que serão explicadas à frente, as seguintes: 25 mulheres que estão fazendo a nova literatura brasileira; + 30 mulheres que estão fazendo a nova literatura brasileira; Entre nós: contos sobre homossexualidade; Questão de pele: contos sobre preconceito racial.

Em artigo intitulado “Antologias (I)”, publicado no jornal eletrônico Rascunho, ${ }^{2}$ afirma:

As antologias servem, de maneira geral, para evidenciar e consolidar nomes, e serão tanto mais significativas quanto maior a capacidade de apreensão do "espírito do tempo" demonstrada pelo responsável pela recolha dos autores. Ao fim e ao cabo, trata-se de um esforço para tornar canônicas as obras escolhidas, ou seja, para normatizar o gosto literário, baseado em interesses os mais diversos, sejam da sociedade, do mercado editorial ou de grupos, marginalizados ou não. Assim, eleito um “critério" (tema e região de origem aparecem com maior frequência), escritores sobejamente conhecidos são reunidos a outros em processo de reconhecimento, numa mistura que intenta avalizar estes pela respeitabilidade daqueles. Mesmo as seletas geracionais, que prescindem dessa mescla, necessitam, para serem aceitas, de um garantidor, que pode ser o autor de prestígio que assina a apresentação do livro, a editora que empresta crédito ao projeto, ou o grupo que sustenta a ação (RUFFATO, 2013, p.11).

Destaco três aspectos mencionados pelo escritor, como necessários, para a elaboração de uma antologia: 1 - a apreensão do "espírito do tempo", que talvez, possamos chamar, não sem receio, de "representatividade”; 2 - os “critérios” e 3 - a “normatização de um gosto”. A apreensão do “espírito do

\footnotetext{
${ }^{2}$ http://rascunho. com.br/wp-content/ uploads/2013/04/ Book_Rascunho_97. pdf
} 
tempo" seria uma atribuição do organizador e, talvez, requeira a percepção de tendências, recorrências, rupturas, revelando o caráter sociológico que toda antologia deve conter. Caráter sociológico no seu sentido stricto, de estudo dos comportamentos sociais que certamente estarão refletidos na literatura de um determinado tempo. Os "critérios" ficam a cargo do organizador ou mesmo da proposta editorial e são condição sine qua non para a organização de uma antologia, diria mesmo, sua condição de sobrevivência, o que empresta ao recorte ou à seleção, coerência interna e razão para as possíveis reterrritorializações que um texto sofre ao migrar de sua condição primeira de produção para um outro local de enunciação. Os critérios seriam, de certa forma, uma salvaguarda aos impressionismos de gosto e preferências, às ações entre amigos etc. Já a “normatização de um gosto” acaba por ser a consequência desejada pelo organizador, pela editora, caso a antologia vingue em seu propósito de seleção. "Normatizar um gosto” pode implicar a construção de um cânone, incluindo novos autores e excluindo outros.

Nesse sentido, é interessante observar as considerações que o professor italiano Giorgio de Marchis faz, na apresentação de Lusofônica, “coletânea antológica”, acerca do inevitável processo de exclusão e renúncia que se opera na organização e seleção de uma obra de tal natureza. Quem o faz, deve explicitar suas intenções e critérios, sob pena de recair em pretensões generalistas:

Os critérios que orientaram a preparação desta antologia são o resultado de uma abordagem prudente da Lusofonia. Não vou me alongar sobre o fato de que, como qualquer coleção antológica, a Lusofônica também é uma seleção que não é exaustiva, pois envolveu exclusões. Essa consideração óbvia, consequência do fato de que toda escolha é sempre uma renúncia, é, no entanto, particularmente necessária, uma vez que o horizonte deste livro é deliberadamente supranacional, e dezenove histórias certamente não esgotam o panorama da nova narrativa em língua portuguesa. O primeiro critério adotado é de natureza linguística: todas as histórias, embora provenientes de três continentes e quatro nações (Angola, Brasil, Moçambique e Portugal), foram escritas em português. O horizonte, não obstante alguma literatura que não esteja aqui representada, é, portanto, declaradamente lusófono. O segundo parâmetro é, ao contrário, geracional: os dezenove escritores selecionados são, de fato, todos nascidos nos anos setenta e publicaram seu primeiro trabalho depois de 1995. Apesar de o limite cronológico superior (1970) ter penalizado escritores indiscutivelmente interessantes e de notável qualidade, essa pressuposição parecia indispensável e significativa. Indispensável para restringir um corpus muito amplo; significativo porque esta data, confirmada pelos preciosos testemunhos de Pepetela, Lídia Jorge e Moacyr Scliar, inaugura uma década de extrema importância para a história de todos os países lusófonos ${ }^{3}$ (MARCHIS, 2006, p.10-11, tradução nossa).

Quando, em 2002, o professor e crítico literário Italo Moriconi publicou, pela editora Objetiva, o que, talvez, tenha sido, a primeira das antologias
${ }^{3}$ I criteri che hanno orientato la preparazione di questa antologia sono il frutto di un approccio prudente alla Lusofonia. Non mi dilungherò sul fatto che, come ogni raccolta antologica, anche Lusofônica è una selezione che non si pretende esaustiva, in quanto ha comportato delle esclusioni.

Questa ovvia considerazione, conseguenza del fatto che ogni scelta è pur sempre una rinuncia, è tuttavia in particolar modo necessaria, dal momento che l'orizzonte di questo libro è deliberatamente sovrannazionale e diciannove racconti non esauriscono di certo il panorama della nuova narrativa in lingua portoghese. Il primo requisito adottato è di natura linguistica: tutti $i$ racconti, benché provenienti da tre continenti e da quattro nazioni (Angola, Brasile, Mozambico e Portogallo), sono stati scritti in portoghese. L'orizzonte, nonostante alcune letterature non siano qui rappresentate, è, quindi, dichiaratamente lusofono9. Il secondo parametro $\grave{e}$, invece, generazionale: i diciannove scrittori selezionati sono, infatti, nati tutti negli anni Settanta e hanno pubblicato la loro prima opera dopo il 199510.

Nonostante il limite cronologico superiore (1970) abbia penalizzato scrittori senza 
do boom a que me refiro, Os cem melhores contos brasileiros do século, logo esclareceu, na Introdução, que o desafio colocado pela editora era evitar critérios acadêmicos. Tais critérios a serem evitados não são devidamente explicitados pelo organizador, o que, a meu ver, deixa a seleção refém exclusivamente do julgamento do leitor. Tal ausência de fronteiras e a heterogeneidade temática retroalimentam o mercado editorial com a elaboração de outras tantas antologias. Ainda que se queira definitiva, nenhuma seleção o será, por mais critérios que se empreguem. De fato, cabe ao leitor o julgamento máximo:

Quando fui convidado pela Editora Objetiva para realizar o presente projeto, fiquei entusiasmado com a proposta - escolher os cem melhores contos do século 20 neste momento de virada para o século 21. Vi logo que teria pela frente um trabalho bastante prazeroso, apesar do esforço da pesquisa que me exigiria. Por outro lado, havia o desafio colocado pela editora de que a seleção dos contos se pautasse não em critérios acadêmicos e sim de gosto e qualidade. Para quem, como eu trabalha na universidade há mais de 20 anos, o desafio equivalia a me colocar em cima de uma corda bamba. $\mathrm{Na}$ Academia estamos sempre relativizando todo e qualquer conceito de qualidade. Mas, como leitores 'normais' que simultaneamente somos, pois também curtimos a literatura para além das polêmicas doutrinárias, sabemos muito bem que existem o bom e o ruim, o perfeito e o ridículo, o eterno e o anacrônico. Sabemos bem que sempre é possível separar joio de trigo. Caberá ao leitor desta coletânea julgar como me saí na tarefa e avaliar se os contos aqui apresentados são realmente excelentes, como acredito que todos são (MORICONI, 2002, p. 11).

Embora a divulgação editorial apresente o livro como antologia e use o polêmico adjetivo “melhores”, o seu organizador o chama de “coletânea”, o que parece mais condizente com uma proposta pautada na relatividade do gosto e da qualidade, ainda que sejam os de um acadêmico conhecido.

Os melhores, segundo critérios de gosto e preferência, não são necessariamente os mais representativos, o que parece ser a condição exposta por Ruffato, como necessária à seleção: certo “espírito do tempo”. À frente retomarei a questão da representatividade para associá-la à condição propedêutica da antologia na formação escolar.

Quando tais seleções se apresentam como coletâneas, revistas, cartografias e radiografias, para usar expressões encontradas nos prefácios analisados por mim, o organizador se liberta do peso de promulgar a chancela do "para todo o sempre".

Também eu selecionei as antologias, coletâneas e revistas para o desdobramento dessa pesquisa. Explico os meus critérios: a proposta temática, quando havia; o conhecimento prévio do organizador e a relação com questões identitárias. Não exatamente nessa ordem. Como professora e pesquisadora, foi com essa intenção que fui adquirindo os exemplares para dubbio interessanti $e$ di notevole qualità11, questo presupposto è parso indispensabile e significativo. Indispensabile per restringere un bacino altrimenti troppo ampio; significativo perché questa data, come confermano le preziose testimonianze di Pepetela, Lídia Jorge e Moacyr Scliar, inaugura un decennio di estrema importanza per la storia di tutti i paesi lusofoni (MARCHIS, 2006, p.10-11). 
pensá-los à luz dos Estudos Culturais inicialmente. Mas logo se somaram à intenção primeira as questões relacionadas ao mercado editorial e ao ensino.

São as seguintes, além daquelas já referidas: Geração 90: manuscritos de computador (org. Nelson Oliveira); Os cem melhores poemas brasileiros do século (org. Italo Moriconi); Os cem menores contos brasileiros do século (org. Marcelino Freire); Os apóstolos: doze revelações (org. Márcia Denser.); Primos: histórias de herança judaica e árabe (ogs. Adriana Armony e Tatiana Salem Levy).

$\mathrm{Na}$ análise que proponho, a partir de alguns prefácios dessas obras, mais do que das fichas catalográficas ou classificações de resenhas, busco analisar a intenção do organizador, como instância de autoridade e chancela; sua relação com a editora; os critérios empregados e seu escopo; para então, apontar ganhos, perdas e danos na formação do aluno-leitor.

Antes de ir a elas, é imprescindível ressaltar três aparentes incongruências do ponto de vista da teoria e da crítica literárias:

a. Uma antologia, por definição etimológica, é um florilégio, a seleção do que já está constituído e que, uma vez recolhido, a partir da sua "beleza”, se eternizará, ou seja, constituirá um cânone, um paradigma. Nessa acepção, uma antologia não reuniria textos inéditos, produzidos para tal projeto. Ao contrário, legitimaria uma prática já existente.

b. É possível e desejável olhar a tradição e o passado literários a partir de uma perspectiva presente, mas é problemático já canonizar o presente sem que a medida do tempo e da leitura tenham reservado a determinadas obras o lugar que lhes é devido na cultura de uma nação, de uma região ou na formação sentimental dos sujeitos.

c. Um texto deslocado de seu contexto original de produção, reterritorializado, no sentido derridiano, fratura seus sentidos originais ou ganha nova condição de leitura?

Nesse sentido, os Estudos Culturais ajudam a esclarecer e a desfazer equívocos conceituais ou estratégias editoriais de venda. Os estudos de cultura se voltam para o presente e o entendimento de suas dinâmicas. Como forma de entendimento dos processos sociais que engendram os discursos literários, ou quaisquer outros, dão visibilidade aos agenciamentos de vozes silenciadas pela língua ou pelos códigos de uma cultura que procura uma homogeneidade dominante. Ao tentar descentralizar as forças coercitivas do cânone literário - branco, ocidental e falocêntrico -, por exemplo, dão espaço e voz a escritas silenciadas que foram postas à margem. A politização do literário, como destaca a professora Beatriz Resende, no artigo “A indisciplina dos Estudos Culturais"4, produz ações afirmativas que repensam a cena literária contemporânea resgatando do limbo autores e obras relegados pela crítica literária.

\footnotetext{
${ }^{4}$ RESENDE, B. Apontamentos de crítica cultural. Rio de Janeiro: Aeroplano, 2002.
} 
Como não é possível abandonar a observação da ação do mercado editorial, sob pena de ingenuidade crítica, há de se louvar sua abertura a tais questões como promoção indireta da leitura, mas não se pode deixar de registrar o fio tênue que separa este ganho das estratégias perniciosas de glamourização e marketing das escritas marginais ou "performáticas" para utilizar o conceito de "narrativa performática”, de Homi Bhabha (1998).

\section{Prefácios, catalogação e intenções}

Um prefácio, uma apresentação ou mesmo uma introdução são metatextos imprescindíveis à compreensão da dinâmica de elaboração de uma antologia e dos lugares de leitura que podem vir a assumir tais livros, especialmente, na formação de um aluno-leitor. As fichas catalográficas são também parâmetros de classificação e inclusão das obras na circulação da leitura. As estratégias de divulgação editorial seguem apelos outros que não serão analisados, nesse artigo, mas que certamente interferem no consumo do livro. Já as resenhas e ensaios esclarecem muitas vezes as intenções do projeto e avaliam sua execução.

Como afirmei anteriormente, uma antologia não é uma coletânea apenas. Ou melhor dizendo, não é toda coletânea que pode ser entendida como antologia para fins propedêuticos. Não estou aqui exaltando o lugar do cânone, mas apenas assinalando definições e funções. Se a coletânea ou revista se apresenta como antologia, ela carrega explicitamente a intenção de canonizar obras e autores ou de dar-lhes visibilidade por meio dos critérios escolhidos pelo organizador, lançando luz sobre aspectos não perceptíveis talvez no seu contexto primeiro de enunciação.

Dessa forma, uma antologia deveria se voltar para o já constituído, o já publicado. Ao enquadrar como antologias seletas de textos escritos para um determinado projeto, portanto, textos inéditos, ainda que de autores consagrados, atribui-se às antologias uma nova função: a cartografia do presente. Seja uma cartografia temática, seja uma cartografia identitária. Nesse caso, também cabe ao organizador a função até certo ponto “iluminista”: a de apontar caminhos, perceber tendências, atribuir valor.

Uma coletânea, uma revista, são reuniões de textos, obviamente selecionados, mas que não se apresentam sob o epíteto de "melhores". Melhor ou pior são julgamentos relativos, representatividade é coisa de outra monta, podendo ferir, muitas vezes, certo beletrismo.

Apontada a distinção classificatória da obra Os cem melhores contos brasileiros do século, organizada por Italo Moriconi, categorizada, pelo organizador, como coletânea, mas apresentada como antologia, analisemos alguns outros exemplos:

Em Geração 90: manuscritos de computador, Nelson de Oliveira afirma sem titubeios: "Esta antologia é a realização de um projeto muito 
caro a mim: o mapeamento das minhas origens, o encontro como meus irmãos de sangue e de ringue...” (OLIVEIRA, 2001, p. 7) E em seguida: "Os contos inéditos aqui reunidos são as flores do mal e do bem (a palavra grega anthología significa seleção de flores) do florilégio de uma época” (OLIVEIRA, 2001, p. 7). Acrescenta também: “Esta não é a antologia dos melhores contos da década de 90, mas dos melhores contistas surgidos na década de 90” (OLIVEIRA, 2001, p.11). Nessa Introdução, em momento algum, o organizador a chama de coletânea, fala em projeto e nos critérios empregados para a seleção.

Em 25 mulheres que estão fazendo a literatura brasileira, Ruffato alterna as designações de seu projeto, como também nos prefácios de outros. Ainda que tal alternância pudesse se justificar pela tentativa de evitar repetições lexicais, o caráter semântico e conceitual das palavras antologia e coletânea nos permite inferir que, de fato, está ocorrendo uma refuncionalização das antologias e suas propedêuticas ou caberá ao leitor tal discernimento?:

É possível organizar um livro de contos que reúne mais de duas dezenas de escritoras, somente levando em conta aquelas que começam a publicar na década de 90, e ainda ficar com a sensação de estarmos sendo injustos, ao deixar de fora, talvez, igual número de autoras que, por um motivo ou outro, infelizmente não têm seus nomes inscritos nesta coletânea (RUFFATO, 2004, p.7).

Para, depois, em um mesmo parágrafo ponderar:

Sobre as mulheres enfeixadas nesta antologia, algumas palavras. Como em tudo há que estabelecer parâmetros, eis o deste livro: todas que aqui estão começaram a publicar prosa de ficção a partir de 1990. Não houve limite de idade, tema, ideologia, estilo ou extensão do trabalho, apenas exigiu-se ineditismo dos textos. Portanto, trata-se de uma coletânea que se quer panorâmica e não se arroga definitiva, nem em relação aos nomes, nem à qualidade dos textos. Ao leitor, à leitora, caberá, identificando-se com essa ou aquela tendência, sinalizar sua estrada no intuito de percorrê-la mais detidamente. São apostas que convido-o (a) a fazer (RUFFATO, 2004, p. 2004).

Os apóstolos: doze revelações, organizada pela escritora Márcia Denser, é mais uma das antologias temáticas da coleção Prosa Presente da editora Nova Alexandria. Na Introdução, Denser apresenta os contistas como "escritores profissionais” e afirma o seguinte: "Todos os contos desta antologia são inéditos, porque antes de tudo foram um desafio. Contudo, como o tema - o apostolado - é sedutor, a identificação do escritor com o personagem histórico também é um fato, tanto quanto a utilização da primeira pessoa do narrador”. (DENSER, 2001, p. 8).

Minha proposta, com esse breve levantamento de classificações, categorizações e intenções, foi avaliar as implicações tanto dessa cena da 
produção literária brasileira quanto dos empreendimentos editorais em relação à formação escolar do jovem leitor. Que fique claro que nem os autores envolvidos nesses projetos nem o mercado editorial têm como alvo o leitor em formação. Essas são uma preocupação e uma associação da minha pesquisa.

\section{Considerações finais: perdas, ganhos e danos}

Como essa não foi uma pesquisa de caráter diacrônico nem empírico, não há nela propriamente um caráter evolutivo, mas tão somente alguns possíveis diagnósticos a partir do material analisado e do lugar que hoje ocupa a leitura literária no âmbito escolar. Os PCN (2000) falam insistentemente na formação de um leitor competente, ou seja, aquele capaz de compreender competentemente um enunciado, a partir de inferências, deduções, associações. Alguém que saiba, de forma relacional e interativa, construir significados a partir do que lê. Sendo a literatura um sistema que se constrói sobre outro, ou seja, sobre o código de uma língua, tensionando-a e potencializando-a em seu grau máximo, a possibilidade de sua rejeição é enorme diante de leitores que sequer depreendem a referencialidade dos signos linguísticos e de professores tão pouco leitores ou estagnados na leitura do cânone e sem interesse nas relações dialógicas estabelecidas pela literatura contemporânea. Professores reféns, às vezes, de um beletrismo inútil, dissociado de qualquer perspectiva histórico-cultural capaz de fazer significar o que é lido. Quando abandonam a perspectiva historiográfica do estudo literário, não sabem o que fazer com o "livro palermo", em suas mãos ou telas, como já dissera Mário de Andrade.

Nesse cenário, identifico algumas vantagens: a) A indicação da leitura - sempre a ser feita de forma mediada - de antologias cujo critério temático ou identitário interesse o leitor da comunidade estudantil com a qual se está trabalhando. Desperto e refeito o interesse pela leitura, o professor deveria ir abrindo o leque ou puxando os fios do novelo de forma a conduzir os alunos às devidas contextualizações originárias de cada texto e autor, no caso de uma antologia no seu sentido paradigmático. No caso da recolha de textos inéditos (feitos para aquele projeto), podem ser trabalhados o estilo pessoal de cada escritor, suas outras obras, as relações intertextuais estabelecidas. Se bem escolhidas, uma antologia ou coletânea podem ser o ponto de partida para o ingresso no universo literário, para além das contribuições antropológicas, sociológicas ou filosóficas que podem oferecer; b) A outra vantagem seria a ideia de panorama. Em cursos introdutórios, panoramas são sempre importantes, uma vez que neles talvez seja possível recuperar o "espírito de um tempo", a que se referiu o escritor Luiz Ruffato. E aqui reafirmo o caráter de intervenção que uma antologia deve possuir. Organizar uma antologia ou mesmo uma coletânea não deixa de ser um trabalho de crítica literária, de estabelecimento de critérios e parâmetros, de busca de 
uma representatividade geopolítica, cultural, estilística, identitária, por mais heterogêneos que sejam seus autores e obras.

As desvantagens podem ser contornadas por um professor mediador que tire proveito até das preferências e gostos duvidosos dos organizadores, apresentando argumentos de contraposição literária. A aparente descontextualização ou reterritorialização de um texto migrado para um outro local de enunciação deve ser motivo para análise de suas novas significações. $\mathrm{O}$ único temor a ser evitado, em cursos propedêuticos, é o vale-tudo que relega a literatura a uma condição ainda mais marginal e periférica do que a que tem ocupado diante de outras artes e linguagens. Ainda que concordemos com o diagnóstico que a literatura não é mais o centro da cultura, como professores e pesquisadores, não podemos contribuir para seu crescente obscurantismo.

\section{Referências}

BHABHA, H. O local da cultura. Belo Horizonte: Editora UFMG, 1998. DENSER, M. (org.). Os apóstolos: doze revelações. Rio de Janeiro: Nova Alexandria, 2001.

FREIRE, M. Os cem menores contos brasileiros do século: São Paulo: Ateliê Editorial, 2004.

KIEFER, C. et al. Pátria estranha: histórias de peregrinações e sonhos. São Paulo: Nova Alexandria, 2002.

MARCHIS, G. (org.). Lusofônica: la nuova narrativa in lingua portoghese. Roma: La Nuova Frontiera, 2006.

MORICONI, I. (org.). Os cem melhores contos brasileiros do século. São Paulo: Objetiva, 2002.

São Paulo: Objetiva, 2001.

Os cem melhores poemas brasileiros do século.

OLIVEIRA, N. (org.). Geração 90: manuscritos de computador. Os melhores contistas brasileiros surgidos no final do século XX. São Paulo: Boitempo Editorial, 2001.

BRASIL, Secretaria da Educação Média e Tecnológica. Parâmetros Curriculares Nacionais para o Ensino Médio. Brasília: MEC, 2000.

RESENDE, B. Apontamentos de crítica cultural. Rio de Janeiro: Aeroplano, 2002.

REVISTA GRANTA. (org). Granta 9: os melhores jovens escritores brasileiros. Rio de Janeiro: Objetiva, 2012.

RUFFATO, L. (org.). Entre nós: contos sobre homossexualidade. Rio de Janeiro: Língua Geral, 2007. 
. Questão de pele: contos sobre preconceito racial. Rio de Janeiro: Língua Geral, 2009.

25 mulheres que estão fazendo a nova literatura brasileira. Rio de Janeiro: Record, 2009.

+ 30 mulheres que estão fazendo a nova literatura brasileira. Rio de Janeiro: Record, 2010.

Recebido em agosto/2018.

Aceito em dezemro/2018. 